\title{
O humanismo na perspectiva de estudantes de Medicina da UFAL
}

\author{
Humanism from the perspective of medical \\ students at UFAL
}

\author{
Cristina Camelo de Azevedo ${ }^{\mathrm{I}}$ \\ Maria Auxiliadora Teixeira Ribeiro ${ }^{\mathrm{I}}$ \\ Sylvia Helena Souza da Silva Batista ${ }^{\text {II }}$
}

\author{
PALAVRAS-CHAVE \\ - Humanismo \\ - Humanização da assistência \\ hospitalar \\ - Estudantes de Medicina \\ - Educação médica \\ - Relações médico-paciente
}

\begin{abstract}
R E S U M O
Este artigo apresenta uma pesquisa que analisa as concepções de humanismo e suas contribuições para a formação médica, na ótica discente, no âmbito do curso de Medicina da Universidade Federal de Alagoas, no período compreendido de novembro de 2006 a julho de 2007. A metodologia escolhida foi a de realização de cinco grupos focais, nos quais foram coletados os depoimentos de 73 estudantes, analisados posteriormente por meio de referencial sobre as práticas discursivas. Os resultados encontrados destacam três aspectos acerca do que o estudante observa e vivencia: na relação com a instituição, o curso e os sentimentos que surgem no seu processo como aprendiz; sobre a relação aluno-professor no curso médico; e, por fim, sobre a relação médico-paciente e demais pessoas com quem o médico interage em seu exercício profissional. Surgiram elementos indicativos de um aprendizado entremeado de sinais de contrariedade, irritação, impaciência e intolerância com os professores e seus métodos e com a instituição. A humanização não é sentida nas práticas pedagógicas da formação médica, embora seja priorizada nos espaços formais iniciais do curso médico.
\end{abstract}

\section{A B S T R A C T}

This article presents the results of a study on humanist concepts and their contribution to medical training from the students' perspective in the School of Medicine at the Federal University in Alagoas, Brazil, from November 2006 to July 2007. The methodology included five focus groups in which statements by 73 students were recorded and subjected subsequently to discourse analysis. The results feature three aspects in: students' observations and experiences in the relationship to the institution and course and the feelings that emerge in their learning process; the student-faculty relationship during medical school; and the physician-patient relationship and physicians' interaction with others during their professional practice. The study detected elements that indicate a learning process interspersed with signs of dissatisfaction, irritation, impatience, and intolerance towards professors and their teaching methods and the institution. Humanization is not perceived in the teaching practices during medical training, although it is prioritized in the initial formal spaces of medical school.

\footnotetext{
${ }^{I}$ Universidade Federal de Alagoas, Maceió, Brasil.

II Universidade Federal de São Paulo, Santos, Brasil.
} 


\section{INTRODUÇÃO}

A educação é um ato intransitivo, quer dizer, o educador não pode transformar a outrem que não esteja se transformando no próprio trabalho de ensinar.

Álvaro Vieira Pinto ${ }^{1}$

Ingressamos no século 21 incentivados a analisar as condutas ético-humanistas que vêm sendo motivo de interesse e preocupação de profissionais e estudiosos que analisam a formação para a área de saúde e as práticas nela realizadas. O termo humanismo e seus equivalentes nas várias línguas surgiram em meados do século 15, no período do Renascentismo. Para os autores latinos, humanitas era uma palavra que significava algo próximo à educação e formação do homem, à semelhança do que os helênicos queriam expressar com o termo paideia. Para o filósofo francês André Comte-Sponville ${ }^{2}$, a palavra humanismo significa considerar a humanidade um valor supremo. Para ele,

a verdadeira questão é saber se devemos crer no homem (humanismo teórico) para querer o bem dos indivíduos ou se podemos querer seu bem (humanismo prático) mesmo tendo todas as razões para não nos iludir quanto ao que são [...] Não é porque os homens são bons que devemos amá-los, é porque não há bondade sem amor [...] Não é preciso crer no homem para querer o bem dos indivíduos e o progresso da humanidade (p. 285-286).

Outro modo de pensar que contribuiu para a compreensão da complexidade que reveste a humanização das relações humanas é a que toma como base a filosofia do diálogo de Martin Buber ${ }^{3}$, que investiga a relação de reciprocidade existente entre o binômio EU-TU ou EU-ISSO, em que TU é o Outro com quem nos relacionamos como pessoa e por intermédio dele nos desenvolvemos, e ISSO é a experiência objetal. Durante todo o processo de educação do ser humano, a presença do Outro, nas mais variadas formas de interação, contribui, altera ou reforça o Eu, mesmo quando essa relação também se estabelece de forma utilitária, por dominação ou controle, como é o caso do binômio EU-ISSO.

No contexto da formação para a área de saúde, Nogueira ${ }^{4}$ recomenda que, para alcançar uma meta diferenciada no campo da humanização das relações assistenciais, deve-se investir, desde o início, na formação dos futuros profissionais. Programas de recepção a estudantes no início dos seus cursos, visando facilitar sua integração a um novo e complexo ambiente como a universidade, têm constituído uma medida positiva para que esse novo profissional, ao ser acolhido, possa compreender a importância de replicar essa prática posteriormente. No decorrer do curso, devem fazer parte do currículo os conteúdos humanísticos que incitem discussões sistemáticas sobre conteúdos bioéticos, morais, culturais, psicossocia- is, alimentados, com o passar dos anos, pelas práticas vividas pelos alunos. Ainda hoje é comum a desconsideração a manifestações psíquicas do paciente, levando o médico a optar por condutas pouco adequadas para o atendimento das necessidades do paciente. A autora também sugere que se disponibilize para os docentes um programa de preparação pedagógica, que não tem sido priorizado nos ambientes universitários.

Batista e Silva ${ }^{5}$ refletem que "quando o docente estrutura sua tarefa, precisa pensar no outro que aprende". E numa investigação realizada com pós-graduandos acerca dos atributos de um bom professor em saúde, identificaram características vinculadas às seguintes dimensões: domínio científico, ter experiência como profissional, ter conhecimentos didático-pedagógicos, ter atitudes humanizadoras com os estudantes, saber ouvir, ter paciência com o não saber do aluno, estimular a pesquisa e gostar de ensinar. Para Maia6 " "os currículos tradicionais na área da saúde seguem uma lógica positivista, em consonância com a visão mecanicista do homem que perpassa as concepções dos formadores".

Ao fazer a leitura desses recortes teóricos e estabelecer uma vinculação com as competências desejadas para o profissional de medicina, descritas no artigo $5^{\circ}$ das Diretrizes Curriculares Nacionais do Curso de Graduação em Medicina ${ }^{7}$, vê-se que a preocupação com o desenvolvimento de um médico saudável de corpo e mente, comprometido com a comunidade em que está inserido e educador por concepção, tem atravessado os tempos.

O processo de preparação para a reestruturação do currículo médico da Universidade Federal de Alagoas iniciou-se em 1999, contando com a participação de docentes, técnicos e alunos. Em 2002, foram realizadas várias oficinas de diagnóstico do curso. Nessas oficinas, apareceram como elementos dificultadores, apontados pelos próprios professores, o descompromisso do docente ou profissional médico com os alunos, identificado por meio do descuido com a definição, elaboração e manutenção do espaço de aprendizagem; a inabilidade, caracterizada por um descaso com a dor e a vergonha do outro por estar doente, no trato com pacientes atendidos nos campos de práticas; e a estimulação proposital do medo do aluno para com o fracasso e o erro, transformando o ato de aprender em uma tortura. Emergiu, também, a conduta individualista do médico enquanto membro de uma equipe multiprofissional.

Neste contexto, realizou-se uma investigação sobre a questão do humanismo no curso de Medicina da Ufal com o objetivo central de analisar as concepções de humanismo e suas contribuições para a formação médica, na procura de compreender quais os sentidos que permanecem para os estudantes sobre o que eles aprendem e vivenciam no curso médico. 


\section{A PESQUISA}

A pesquisa foi divulgada no âmbito do curso, no período compreendido entre novembro de 2006 e fevereiro de 2007, mediante reuniões da Faculdade com os alunos, no Centro Acadêmico e nas salas de aula. Dos cinco grupos focais constituídos participaram 73 estudantes, sendo 29 do primeiro ano, 10 do terceiro, 17 do quarto e 17 do sexto ano. Cada reunião teve a duração de duas horas, perfazendo um total de dez horas de coleta de informações. Dois estudantes do curso de Psicologia da Ufal foram capacitados para acompanhar, gravar e anotar as falas, condutas e outros aspectos significativos das reuniões.

Segundo Nogueira-Martins e Bógus ${ }^{8}$ o processo de coleta de dados - grupo focal - pode ser utilizado para identificar conceitos, crenças, percepções, expectativas, motivações e necessidades de um grupo específico e, posteriormente, essas informações podem ser aproveitadas para subsidiar programas de intervenção.

Foi usado um roteiro simples de quatro perguntas, previamente testado: $\mathrm{O}$ que lhe vem à mente quando se fala em humanismo? Que ideia de humanismo tem sido desenvolvida no curso de Medicina? Durante o curso, que experiências ou situações você considera que têm contribuído para a formação humanista do/a estudante? Como foi participar dessa discussão?

A constituição dos grupos focais foi alcançada após a superação de algumas dificuldades iniciais em função de o horário disponível dos estudantes ser dificultado pelo número de horas investidas no curso. Foi solicitada a ajuda de alguns professores, que nos cederam seus espaços de sala de aula para realizar a pesquisa com os alunos que se oferecessem para isto. Todas as reuniões foram realizadas em ambientes da Ufal, previamente preparados para garantir a manutenção da privacidade e o afastamento das demandas externas, que geralmente prejudicam a atenção dos grupos.

O referencial metodológico que fundamentou a análise das falas desenvolvidas nos grupos focais foi o das práticas discursivas de Spink", conceituado como a "linguagem em ação, isto é, as maneiras a partir das quais as pessoas produzem sentidos e se posicionam em relações sociais cotidianas". As falas foram transcritas e analisadas, considerando-se inclusive as observações feitas sobre gestos, interpolações de resistência entre duas ou mais pessoas, exacerbação de emoções, dificuldades de compreensão das perguntas, imprecisão ou assertividade das respostas, ansiedades de cada um dos grupos. Por último, foi elaborado um mapa descritivo das falas, no qual se destacaram seis categorias gerais, a partir das quais os conteúdos foram organizados, tendo-se o cuidado de preservar a sequência das falas, evitando, assim, descontextualizá-las. As seis categorias foram: 1. Expressão de valores virtuosos; 2. Influências do processo de educação em geral; 3. Relação médico-paciente vivenciada (ou interpretada) a partir da formação médica; 4. Relação aluno-professor; 5. Reconhecimento/convivência com perspectivas e limites profissionais, sentimentos e emoções; 6 . Influências do contexto mercantilista na prática médica.

A seguir, exemplificamos como os mapas foram formados:

Para a compreensão do mapa, é importante observar que a leitura vertical das colunas possibilita a leitura dos repertórios, enquanto a leitura horizontal permite a compreensão da dialogia. Após a formação do mapa, foi realizada uma leitura mais ampla dos sentidos nele expressos, por meio das categorias estabelecidas. O material coletado foi volumoso e, por conta disso, das quatro perguntas feitas aos alunos, aprofundamos, até o momento, apenas as duas primeiras, por terem fornecido um corpo de ideias suficiente para procedermos à reflexão acerca do tema humanismo no curso médico e dos objetivos que nos propusemos alcançar.

\section{RESULTADOS E DISCUSSÃO}

Três aspectos ficaram visíveis, tanto durante a realização dos grupos focais, quanto na análise das falas. Em alguns momentos, não foi possível fazer recortes precisos na análise desses aspectos, visto que as relações entre eles estavam ora imbricadas, ora interdependentes.

O que os alunos observam acerca da instituição, do curso e sobre si próprios no papel de aprendizes

Este aspecto mostra um ato de aprender entremeado de sinais de contrariedade e irritação por estarem na situação de aprendizes, emoções essas que foram captadas por meio das palavras e tonalidade das vozes, ora intensas, ora contidas, ora impacientes, ao abordarem as diferentes situações, vividas e atribuídas às condutas dos professores, a seus métodos ou à forma indiferente como percebem que a instituição trata das demandas ou solicitações dos discentes.

[...] A universidade está tentando formar profissionais humanos... Ela está sempre focando a relação médico-paciente, que o médico tem que ser humano. Só que em minha opinião é uma hipocrisia, porque, na verdade, ela só fala, mas quando chega ao final, temos mil coisas pra fazer, vários trabalhos... estamos cansados e vamos por obrigação para as aulas que deveriam ser humanizadas. ( $1^{\circ}$ ano $)$

[...] Temos visto a Faculdade como um lugar de muito trabalho, muito estresse e de grande cobrança, mesmo não sendo formados ainda. Não temos o tempo necessário para cuidar de nós mesmos. ( $6^{\mathrm{o}}$ ano $)$

Milan et al. ${ }^{10}$, ao analisarem o universo psíquico do estudante de Medicina, verificaram que os estudantes dos primeiros anos, após uma fase de euforia, ocorrida logo após o ingresso na Faculdade, passam para a fase de desencanto com as aulas, com os professores, queixando-se da "má didática das aulas, ao volume 
1a pergunta: $O$ que lhe vem à mente quando se fala em humanismo?

\begin{tabular}{|c|c|c|c|c|c|c|}
\hline \multirow[b]{2}{*}{ Série } & \multicolumn{6}{|c|}{ CATEGORIAS } \\
\hline & $\begin{array}{l}\text { Expressão de } \\
\text { valores virtuosos }\end{array}$ & $\begin{array}{l}\text { Influências do } \\
\text { processo de } \\
\text { educação em geral }\end{array}$ & $\begin{array}{l}\text { Relação } \\
\text { médico-paciente }\end{array}$ & $\begin{array}{l}\text { Relação } \\
\text { aluno-professor }\end{array}$ & $\begin{array}{l}\text { Reconhecimento / } \\
\text { convivência com } \\
\text { perspectivas e limites } \\
\text { profissionais, } \\
\text { sentimentos e } \\
\text { emoções }\end{array}$ & $\begin{array}{l}\text { Influências do } \\
\text { contexto } \\
\text { mercantilista } \\
\text { na prática } \\
\text { médica }\end{array}$ \\
\hline 3 ANO & $\begin{array}{l}\text { - É estar próximo do } \\
\text { ser humano, ter } \\
\text { amor, satisfação } \\
\text { com o outro, } \\
\text { empatia. } \\
\text { - É tratar o paciente } \\
\text { com dignidade e } \\
\text { respeito, sem faltar } \\
\text { com a verdade. }\end{array}$ & $\begin{array}{l}\text { - É não se envolver } \\
\text { tanto com o } \\
\text { paciente, porque, } \\
\text { na nossa profissão, } \\
\text { envolver-se demais } \\
\text { acaba prejudicando } \\
\text { a nós mesmos, mas } \\
\text { também não } \\
\text { deixando o } \\
\text { paciente à toa. }\end{array}$ & & & $\begin{array}{l}\text { - É ter consciência... } \\
\text { acho que consciência é } \\
\text { muito importante... } \\
\text { saber as ideias de cada } \\
\text { um... é saber criticar } \\
\text { mas também saber } \\
\text { aceitar a opinião dos } \\
\text { outros. } \\
\text { - É ter sensibilidade } \\
\text { para perceber as } \\
\text { emoções dos outros. }\end{array}$ & \\
\hline \multicolumn{7}{|c|}{ 2a pergunta: Que ideia de humanismo vem sendo desenvolvida no curso de Medicina? } \\
\hline 4 ANO & & & $\begin{array}{l}\text { - É essa questão da } \\
\text { relação do médico } \\
\text { com o paciente... } \\
\text { desde o que é } \\
\text { abordado na } \\
\text { psicologia médica, } \\
\text { até a questão do } \\
\text { que o médico } \\
\text { espera do paciente, } \\
\text { e o paciente, do } \\
\text { médico. }\end{array}$ & $\begin{array}{l}\text { - É o que tem } \\
\text { sido abordado } \\
\text { na psicologia, } \\
\text { nas aulas de } \\
\text { Saúde \& } \\
\text { Sociedade, mas } \\
\text { deveria ser } \\
\text { abordado em } \\
\text { todas as clínicas, } \\
\text { principalmente } \\
\text { por aqueles } \\
\text { professores que } \\
\text { estão nos } \\
\text { ambulatórios, } \\
\text { muito mais do } \\
\text { que pela } \\
\text { professora de } \\
\text { Saúde \& } \\
\text { Sociedade, que } \\
\text { nunca atendeu } \\
\text { pacientes. }\end{array}$ & $\begin{array}{l}\text { - Veja a história da } \\
\text { gente: primeiro ano, } \\
\text { falar de humanização, } \\
\text { quando a gente teve } \\
\text { contato com o cadáver } \\
\text { em Anatomia. No } \\
\text { terceiro ano, a gente } \\
\text { debate com a Bioética } \\
\text { levando em conta que } \\
\text { a Bioética é uma } \\
\text { matéria eletiva... } \\
\text { depois, Saúde \& } \\
\text { Sociedade, a que a } \\
\text { maioria não dá muito } \\
\text { valor... } \\
\text { - Aí vem o terceiro } \\
\text { ano, a gente se debate } \\
\text { com a Psicologia e a } \\
\text { Psiquiatria Médica... }\end{array}$ & \\
\hline
\end{tabular}


excessivo de estudo e à pouca utilidade dos cursos, vistos por eles como teóricos e afastados da Medicina em si" (p. 78). Para esses autores, o desencanto do estudante aumenta porque ele não consegue perceber que enfrenta uma fase de transição nunca experimentada, na qual passa de um sistema paternalista de ensino para outro mais autônomo, em que precisa criar seu próprio método de estudo.

Essas críticas persistiram nos grupos de alunos do quarto ao sexto ano. Tassara e Damergian ${ }^{11}$, ao estudarem a construção da subjetividade do sujeito, refletem sobre o quanto tem sido difícil afirmar a identidade psíquica e social, manter a autonomia e participar criticamente da realidade dentro das condições que a sociedade atual impõe. As trocas indispensáveis à subjetividade são marcadas pela rejeição, pelo ódio, pela indiferença. Os investimentos afetivos na sociedade contemporânea são, em grande parte, da mesma ordem, ou seja, falta amor, fundamento para a bondade e o caráter. As pessoas são coisificadas, e as coisas, personalizadas.

Para o aluno, a coisificação das pessoas e a personalização de coisas acontecem no curso e na universidade quando ele sente que seu cansaço, suas reivindicações e seu adoecimento não importam tanto quanto o cumprimento de prazos de entrega de trabalhos e a frequência assídua às atividades acadêmicas.

[...] Temos vivenciado situações de perder provas devido a doenças, mas, mesmo assim, não temos o direito de fazer segunda chamada. O professor é médico, nos tem visto doentes, mas ainda assim não nos permite fazer uma reavaliação. Quando conseguimos fazê-la, temos que enfrentar uma burocracia enorme, precisando que alguns alunos recorram à junta médica [...] Nós não nos sentimos humanos aqui. Temos vivenciado aquela famosa frase: "interno não é gente, residente não é médico". Esse é o lema do humanismo aqui dentro. (6ำ ano)

Em outros momentos, os estudantes se veem impossibilitados de aprender condutas humanizadoras, ora porque se consideram tolhidos pelo que vivenciam no curso, ora porque acreditam que chegaram à escola com um saber já constituído sobre essa questão durante seus estágios anteriores de vida.

[...] Isso não se ensina... [...] Mas eu acho que não leva a nada. Eu acho que, por mais que se ensine a ser humano, tem que partir da pessoa. ( $3^{\circ}$ ano)

[...] O humanismo também vem da sua educação e da sua vivência. Por exemplo, uma pessoa que tem algum tipo de preconceito não vai conseguir nunca ser humana. [...] Mesmo que ela escute na Faculdade, milhões de vezes, que ela deve tratar as pessoas de forma igual, ela não vai conseguir. ( $1^{\circ}$ ano).
Para compreender essas visões dos alunos sobre a descrença na capacidade da escola em ensinar condutas humanísticas, nos reportamos aos estudos de Barrere e Martuccelli ${ }^{12}$, que apresentam a escola como um campo que se vê, hoje, incapaz de reconhecer a legitimidade das preocupações éticas contemporâneas acerca das relações do sujeito consigo próprio, com o outro e com a sociedade. Para os autores, a modernidade produziu um relativismo moral que deu espaço ao fortalecimento do individualismo e do utilitarismo como ideais pessoais.

[...] Tem aluno que já chega com o pensamento de que vai cursar medicina para ganhar dinheiro, ficar rico, ganhar status e esquece o lado humanista. Tem alunos que chegam... que são esforçados, querem ajudar, tudo isso. A realidade é essa. Tem muitas pessoas que, infelizmente, estão no curso por status, só pra ganhar dinheiro. ( $3^{\circ}$ ano).

Para esses autores, a modernidade desenvolveu um individualismo vazio, centrado em duas grandes concepções de individualismo: uma é centrada no desempenho, na capacidade de domínio do ambiente, uma racionalidade que é instrumental e estratégica; a outra se baseia na expressão, no desejo de fazer valer sua autenticidade.

Esse duplo individualismo aparece claramente nos discursos dos discentes, alternando as ideias que se voltam ora para a preocupação com o desempenho, ora para a vontade de ser autêntico, mantendo a integridade do ser e não precisando se metamorfosear para participar da realidade vivida. Algumas falas expressaram as ocasiões em que a preocupação com o desempenho prevalece, tal como:

[...] a técnica que a gente vai adquirindo no curso diminui também o humanismo. Por exemplo, no primeiro ano, a gente disseca cadáveres... “Minha filha, vocêvai abrir o cadáver... você tem que ter respeito" (a aluna recorda o que disseram a ela). Tem que ter respeito, mas chega um momento que está uma coisa tão técnica, está-se tão preocupada em saber como funciona, que você termina esquecendo que ali existia um ser humano [...] Numa aula prática de Semiologia, eram dez pessoas. Tem condições de dez pessoas apalparem o mesmo paciente? Todo mundo estava vendo aquele paciente como um objeto. ( $3^{\underline{o}}$ ano)

As questões éticas e humanísticas dos alunos continuaram a surgir nos discursos quando criticaram o curso médico pelo excesso de exigências voltadas para o aumento da competência técnica, incitando-os a participar de uma luta acirrada para serem os melhores. 
[...] É muito concorrido o curso de Medicina. O estágio... eu sinto que tem uma concorrência entre os alunos [...] A própria instituição estimula a concorrência. Por exemplo, quem passou em primeiro lugar no vestibular ganha uma bolsa de um ano. Em vez de estimular a estudar, estimula a concorrer com seu amigo, seu colega [...] São os seis anos assim! ( $3^{\circ}$ ano)

Ou então, quando percebem que terão que ser persistentes para manterem os valores éticos que referendam o que é ser uma "boa pessoa" ou ter uma "boa vida", embora pensem que o que se passa no contexto social não é de sua responsabilidade:

[...] Eu penso em humanismo como uma relação mais harmônica em toda a sociedade, evitando essa relação tecnicista, mecanicista que o homem tem hoje, e buscar uma relação mais de conforto e vivência, uma relação mais de acolhida, diminuindo um pouco as intrigas, a concorrência... porque a gente não faz isso porque quer, mas porque nos obrigaram a isso... a ter essa visão tecnicista, a identificar as pessoas através de números, o doente através da doença. ( $3^{\circ}$ ano)

Com as linhas do rosto endurecidas e a tonalidade da voz demonstrando indignação e recriminação, um aluno expressa:

[...] O humanista é visto como um cara esquisito. O cara que perde seu tempo com a questão social é considerado um idiota. O humanista também é em menor número. E essa maioria que o considera esquisito deve concordar com a desigualdade que o sistema provoca, com as crianças morrendo de fome, com a privatização da universidade... Ser humanista é muito difícil. ( $1^{\circ}$ ano)

Segundo Piaget ${ }^{13}$, a noção de igualdade evolui junto com o indivíduo e aos poucos ele descobre que pode mudar as regras sem que isso se torne uma transgressão, como antes era percebido. Nesse estágio, a pessoa descobre que pode elaborar, em parte, suas próprias normas. Essa passagem demarca a transição da heteronomia (moral externa, imposta pelas autoridades) para a autonomia (consciência individual).

La Taille ${ }^{14}$ afirma que, assim como a racionalidade e a moral, o tema das virtudes é universal, está presente nas conversas do cotidiano entre os adultos, e entre as crianças. Elas fazem parte do quadro de referências a partir do qual cada um se entende como ser humano, por possibilitarem a todo ser humano uma leitura valorativa de si próprio e dos outros.

O que o estudante tem observado e como tem vivenciado a relação aluno-professor no curso médico

Considerou-se também como docente o profissional médico dos serviços, pois, no momento em que este se relaciona com o aluno para lhe mostrar as práticas médicas, ele assume o papel de pro- fessor, de orientador. Nessa relação, o estudante se sente desconsiderado e pouco acolhido pelos professores em geral. As falas revelaram uma relação distante, que o aluno não quer reproduzir quando estiver formado. Ele percebe também que a universidade como instituição estimula essa maneira de agir dos docentes, quando elabora regras que reforçam os atos "desumanos" do docente para com ele.

[...] Infelizmente o que a gente vê é o que a gente não quer ser [...] Aí é onde está a experiência de ensino. A gente pensa em ser humanista, mas se espelha num profissional que não tem nada de humanista e acaba sendo influenciado por ele [...] A gente pensa que pode mudar e quando chega a hora de fazer, a gente faz do mesmo jeito que eles (professores ou profissionais do serviço) fizeram. ( $3^{\circ}$ ano)

Apesar da existência de posicionamentos como os citados acima, um ou outro professor do curso de Medicina foi tido como descomprometido ou "fácil de enrolar" quando ensejou desenvolver ações mais humanizadoras com o paciente ou com o aluno, tais como compreender a dor do paciente e adiar, naquele momento, o acesso dos estudantes a este, ou então, quando, diante das queixas dos alunos acerca do pouco tempo para estudar as matérias anatomofisiológicas, concluiu a aula mais cedo ou liberou os alunos.

Bohoslavsky ${ }^{15}$ declara que passou por experiências no sentido de modificar as relações tradicionais professor-aluno baseadas no vínculo de dependência, e as resistências enfrentadas foram, em maior grau, por parte dos alunos. Não é à toa que essas relações estabelecidas há séculos, fomentando a verticalidade e não a cooperação complementar, mantiveram-se sem avanços significativos.

Ramos-Cerqueira ${ }^{16}$ afirma que na relação professor-aluno não existe lugar para a subjetividade, para o afeto, e este fato parece ser mais nítido na escola médica, na qual o modelo autocrático e hierárquico predomina do ciclo básico à pós-graduação. É evidente, na relação professor-aluno, a relação entre desiguais, em que ter o saber empresta poder a quem o tem e desqualifica aquele que não o possui, levando a um estilo de aprender em que a passividade e a atitude crítica são as marcas.

[...] Tanto na sala de aula quanto nos ambulatórios, a gente percebe que o médico não tem paciência com o paciente, nem com a gente. A gente fica chocada, nos entreolhamos, mas ninguém chega a falar nada para o professor. Isso fica só entre a gente porque o professor é superior a nós. ( $4^{\circ}$ ano) 
[...] A relação aluno-professor é a pior possível [...] O professor A é muito bom no que ele faz, dá uma excelente aula, nos cobra bastante, mas dizer que a relação que ele mantém com a maioria das pessoas é saudável não é não. (6º ano)

Para Bohoslavsky ${ }^{15}$, como a relação professor-aluno é desenvolvida sob o vínculo da dependência e da submissão, espera-se do professor que ele saiba mais que o aluno, o proteja para que ele não cometa erros, determine a legitimidade de seus interesses e defina o conteúdo, tempo, espaço e condutas dessa relação. Ver o aluno como um eixo central do trabalho pedagógico gera o compromisso de ser mais autêntico e coerente e, por conseguinte, auxiliar os alunos a serem também sujeitos mais autênticos. [...] eles são inacessíveis e o que eles dizem é lei. "Não discuta!", diz uma aluna imitando o jeito de um professor falar. É perder sua nota. (6 $6^{\circ}$ ano)

Nogueira ${ }^{4}$ refere que, entre os desafios para a humanização das relações assistenciais, encontra-se o da exposição dos estudantes a professores e profissionais que nem sempre funcionam como efetivos modelos positivos e estimulantes de atitudes de respeito à vida e à pessoa humana, de compreensão da natureza humana, de valorização dos aspectos psicoemocionais e do entendimento das relações sociais.

[...] Eu vou dar um exemplo sobre o que aconteceu no ano passado, que não depende de uma preparação psicológica, pedagógica. Há um professor que sempre dizia que devíamos tratar o paciente bem, com respeito. Um dia, durante uma aula prática, nós estávamos atendendo determinado paciente, e um outro, num leito ao lado, começou a passar mal e ele (professor) ficou impaciente, incomodado com a situação e não abriu espaço para atender o paciente. ( $4^{\circ}$ ano $)$

Não obstante a existência de críticas, por parte dos alunos, sobre a prática da docência, eles também observaram a contradição existente entre as condições de trabalho do professor e a convocação feita pela instituição para que este se sinta como elemento essencial da melhoria da qualidade do ensino e do progresso social e cultural ${ }^{17}$ : [...] Muitos professores aqui no HU não tiveram um curso de pedagogia, de técnicas e recursos sobre como ensinar ao aluno. ( $4^{\mathrm{o}}$ ano $)$

O que e como o estudante tem observado e aprendido sobre a relação médico-paciente e demais pessoas com quem se relaciona, tais como a família e a equipe multidisciplinar com a qual o médico está sempre em contato

Apareceram, de forma enfática, falas que valorizaram a ação do médico ou professor de atender o paciente dispensando-lhe atenção, cuidado com o ouvir:
[...] Muitas vezes, o paciente precisa apenas de um conselho... às vezes, não é nem do remédio que ele está precisando [...] é apenas escutar, porque o paciente chega com um problema e não quer sair com outro [...] mesmo que vocênão consiga resolver o problema dele como um todo, ele sabe que pode confiar em você. ( $3^{\circ}$ ano).

Segundo Salimon ${ }^{18}$, todo homem é um ser capaz de se aperfeiçoar, e a humanização é um processo pessoal, solidário e holístico que se realiza no sujeito em três níveis de consciência: de si mesmo, de pertencer e de optar.

[...] Você às vezes vai para o médico e ele diz que você tem que ir ao Posto Salgadinho pegar uma ficha para ir a outro médico, que o encaminha para outro e outro, e o paciente fica perdido, sem saber aonde ir. Aí você chega, conversa e pergunta: o que é que você tem? O que é que a gente pode fazer? E isso resolve sem necessidade de tantos encaminhamentos. O médico acha que só ele não pode perder tempo... não entende que o paciente também tem os afazeres dele... ( $3^{\circ}$ ano)

Rego $^{19}$ descreve uma pesquisa que realizou no ano de 2000 numa Faculdade de Medicina, com alunos do quarto ano de graduação, acerca dos valores que os estudantes achavam que deveriam ser assegurados pelo código de ética do médico, ou seja, beneficência, confiabilidade, honestidade, humildade, justiça, paciência, respeito, responsabilidade e solidariedade.

[...] é tratar o paciente com dignidade e respeito, sem faltar com a verdade, também não sendo grosso, respeitando suas vontades e desejos. ( $3^{\circ}$ ano)

[...] é praticar o bem, olhar as pessoas de forma igualitária, mas nunca será possível se despir de todos os preconceitos [...] ter a humildade de pedir desculpas, de reconhecer os erros [...] é preocupar-se com o outro [...] é ser sensível, ser mais coerente com as coisas, ser menos egoísta, ser mais comunicativo, mais educado... Tudo isso está presente na vertente humanista. ( $1^{\mathrm{o}}$ ano $)$

Algumas falas dos estudantes expuseram outra contradição vivida em seu processo de formação médica: ao tempo em que pensam no humanismo como a prática do bem, tratar com equidade, ser humilde, polido, respeitar o paciente, experimentam, na relação médico-paciente, situações que não os auxiliam a reforçar esses valores como profissionais, tais como:

[...] Eu faço um estágio onde os profissionais de saúde, inclusive o médico, não tratam o paciente pelo nome [...] Às vezes se passa um medicamento adequado para a doença do paciente, mas que ele não pode comprar. $\mathrm{O}$ 
médico tem que conhecer a história do paciente e passar um remédio adequado para a sua realidade. ( $4^{\circ}$ ano $)$

Os estudantes também se referiram à precarização da assistência à saúde, que dificulta mais ainda a realização de práticas humanizadas de trabalho, tanto nos hospitais quanto nas unidades de saúde. Entretanto, as falas denotam dúvida sobre se essa precarização aniquila a vontade do profissional de prestar um atendimento cuidadoso, humanizado.

[...] O profissional médico, em alguns locais, é pressionado para atender tantos pacientes! [...] Se você atender rápido, o paciente acha ruim. O que você vai fazer? Vai deixar uma fila interminável e gastar uma hora para cada paciente, se você só vai ter quatro horas numa tarde ou numa manhã? [...] Você pode atender em cinco minutos e o cara achar que você é a pessoa mais humanista do mundo [...] Não é o tempo que conta, mas sim a forma de medicar, de tratar, de dar atendimento. ( $3^{\circ}$ ano)

Sobre o relacionamento que o médico mantém com outros profissionais da área da saúde, os estudantes referem que isso não é comentado durante o curso, pois essa temática só apareceu porque foi provocada pela pesquisadora. [...] Não se fala no curso que nós vamos trabalhar em equipe com nutricionista, psicólogo, enfermeiro [...] Quando você chegar lá (na prática) é que você vai saber. ( $3^{\circ}$ ano)

\section{CONSIDERAÇÕES FINAIS}

Humanismo não é apenas um tema transversal, ele está entranhado na vida em forma de uma rede abrangente de significados que envolvem e entremeiam todas as relações vividas na formação e prática de todas as profissões.

Sobre as principais reflexões feitas ao longo desta pesquisa, a primeira diz respeito às condutas humanísticas descritas pelos estudantes, que falam, na maioria das vezes, da (des)humanidade da prática pedagógica realizada pelos docentes ou pelo médico que lida com alunos, ou ainda pelos funcionários de outras profissões. Algumas falas repercutiram mais do que outras, dentre elas a que aponta a contradição entre a prática e a teoria do docente que age de forma desumanizada. O estudante questiona "como podemos querer ensinar humanismo, praticando atos desumanos na escola". Essa avaliação crítica do aluno nos faz pensar que ensinar a humanização das práticas médicas não tem levado a uma reflexão sobre nossas próprias práticas enquanto docentes. Existe uma preocupação da escola médica com o desenvolvimento de um processo de avaliação contínuo do corpo docente sobre suas práticas pedagógicas e o efeito delas sobre os estudantes?
Por outro ângulo, André Langaney ( apud $\mathrm{Morin}^{20}$ ) ressalta que, no atual estado dos programas de ensino, o estudante não estuda a si mesmo. E isso também é grave. Tudo aquilo que pode ajudar a pensar sobre o que somos é tratado apenas de maneira clandestina por certo número de ensinamentos. Ao que parece, não é apenas o estudante que não se estuda, mas também os docentes, os demais profissionais responsáveis pelas práticas, os gestores do ensino e dos serviços. Enfim, todos os envolvidos no contexto da formação estão mais interessados em estudar o outro e não a si mesmos. Não há como falar em humanização da formação sem abordar o contexto de sociedade em que vivemos atualmente, repensar e repassar em conjunto-gestores, professores, alunos, profissionais e gestores dos serviços - as lições sobre a ética humanística, que abrange a ética da responsabilidade, da justiça, da generosidade, do respeito ao outro, e discutir profundamente sobre como estão sendo praticados esses valores.

Outra reflexão diz respeito ao fato de a orientação humanista requerer uma visão mais sistêmica de mundo, de pessoa, de profissão. No curso médico, pelos dados coletados, essa orientação é desenvolvida (e de forma precária) apenas na relação médico-paciente. O estudante ainda não se vê sendo estimulado a observar e se observar em outros contextos, tais como a sala de aula, os laboratórios, a instituição universitária, os hospitais, as unidades de saúde, as comunidades, a família, a cidade, nos quais todo ser humano pratica a sua humanidade e que são também focos do adoecer humano.

Os estudantes não fizeram praticamente nenhuma menção ao "outro" constituído pela equipe multidisciplinar. $\mathrm{O}$ "outro" parece ainda não caber como ser de importância, porque não pode ser reconhecido dessa maneira se "eu" antes não me reconheço como tal. As experiências de ensino relatadas pelos alunos mostram a ausência do encontro como fenômeno télico, que consiste na capacidade de a pessoa se sentir atraída ou rechaçada por pessoas e objetos ${ }^{21}$. Para o autor, a relação médico-paciente requer sensibilidade télica, que compreende o desenvolvimento e expressão de sensibilidade, reciprocidade e mutualidade. "É o 'clique' intuitivo entre os participantes de uma relação" (p. 19). Essas experiências traduzem um aprendizado voltado mais para o acúmulo de informação (primeira etapa do conhecimento) e carentes de tempo ou propósitos para realizar-se a reflexão (no mínimo) sobre atitudes e ações. Esse tipo de ensino cria um estudante disperso, defensivo, com pouca reflexão interior sobre si e quase nenhuma visão acurada do outro, seja ele seu colega, o docente ou o paciente. São experiências de aprendizagem que se voltam mais para ver o outro como um objeto, baseadas na relação EU-ISSO 3 . 
A humanização da formação médica necessita, dentre outras demandas, de "um outro professor e um outro estudante", mais preocupados em se desenvolverem como "pessoas em sua totalidade", e não apenas nos papéis fragmentados que exercem. Os espaços de escuta dos discentes devem ser cada vez mais ampliados e devemos instituir os espaços de escuta dos docentes, nos quais se possa ter a condição de refletir e decidir que docentes queremos ser.

Por fim, é necessário compreender a humanização como uma política permanente do curso médico, cujo desenvolvimento não se esgota, mas se aprimora com o passar dos anos, mediante avaliações contínuas e inovação das estratégias para fazê-la acontecer.

\section{REFERÊNCIAS}

1. Pinto AV. Sete lições sobre educação de adultos. $10^{\circ}$ ed. São Paulo: Cortez; 1997.

2. Comte-Sponville A. Dicionário filosófico. São Paulo: Martins Fontes; 2003.

3. Buber M. Eu e Tu. $2^{\circ}$ ed. rev. São Paulo: Cortez \& Moraes; 1979.

4. Nogueira MCFM. Humanização das relações assistenciais: a formação do profissional de Saúde. São Paulo: Casa do Psicólogo; 2001.

5. Batista NA, Silva SHS. O professor de medicina. São Paulo: Loyola; 2001.

6. Maia JA. Formação humanística no ensino superior em saúde: intencionalidade e casos. In: Batista NA, Batista SH, Abdalla IG. (org.). Ensino em saúde: visitando conceitos e práticas. São Paulo: Arte \& Ciência; 2005.

7. Brasil. Conselho Nacional de Educação. Câmara de Educação Superior. Resolução CNE/CES n.․․ 4, de 07 de novembro de 2001. Institui Diretrizes Curriculares Nacionais do Curso de Graduação em Medicina. Diário Oficial da União. Brasília, 09 de novembro de 2001; Seção1, p.38.

8. Nogueira-Martins MCF, Bógus CM. Considerações sobre a metodologia qualitativa como recurso para o estudo das ações de humanização em saúde. Saúde e Sociedade. 2004;13(3):44-57.

9. Spink MJ (org.) Práticas discursivas e produção de sentidos no cotidiano: aproximações teóricas e metodológicas. 2. ed. São Paulo: Cortez; 2000.

10. Milan LR, De Marco OLN, Rossi E, Arruda PCV. O universo psicológico do futuro médico: vocação, vicissitudes e perspectivas. São Paulo: Casa do Psicólogo; 1999.
11 Tassara ETO, Damergian S. Para um novo humanismo: contribuições da Psicologia Social. Estud Av. 1996;10(28):291-316.

12. Barrere A, Martuccelli D. A escola entre a agonia moral e a renovação ética. Educ Soc. 2001;22(76):258-277.

13. Piaget J. O juízo moral na criança. São Paulo: Summus; 1994.

14. La Taille Y. Para um estudo psicológico das virtudes morais. Educ Pesquisa. 2000;26(2):109-121.

15. Bohoslavsky RH. A psicopatologia do vínculo professor-aluno: o professor como agente de socialização. In: Patto MHS. Introdução à psicologia escolar. $3^{\circ}$ ed. São Paulo: Casa do Psicólogo; 1997.

16. Ramos-Cerqueira, ATA. A prática pedagógica como processo de comunicação: a relação professor-aluno como eixo: o ponto de vista psicológico. Interface Comun Saude Educ. 1997;1(1):187-191.

17. Nóvoa A. Os professores na virada do milênio: do excesso dos discursos à pobreza das práticas. Educ Pesqui. 1999;25(1):11-20.

18. Salimon LI. Diferencial humanístico para la educación médica de los sentimientos al constructo curricular. Educ Med Super. 2003;17(1):58-64.

19. Rego S. A formação ética dos médicos: saindo da adolescência com a vida (dos outros) nas mãos. Rio de Janeiro: Ed. Fiocruz; 2003.

20. Morin E. A religação dos saberes: o desafio do século XXI. $2^{\underline{o}}$ ed. Rio de Janeiro: Bertrand Brasil; 2002.

21. Fonseca Filho JS. Psicodrama da loucura: correlações entre Buber e Moreno. São Paulo: Agora; 1980.

\section{CONTRIBUIÇÃO DOS AUTORES}

A autora Cristina Camelo de Azevedo colaborou como investigadora, e as autoras Maria Auxiliadora Teixeira Ribeiro e Sylvia Helena Souza da Silva Batista colaboraram respectivamente como co-orientadora e orientadora, participando de todos os momentos da elaboração do artigo.

\section{CONFLITO DE INTERESSES}

Declarou não haver.

\section{ENDEREÇO PARA CORRESPONDÊNCIA}

Cristina Camelo de Azevedo

Rua Desembargador Valente de Lima, 432/202

Mangabeiras - Maceió

CEP: 57037-030 AL

E-mail: cricaza@ig.com.br 